\title{
Procedure to Match the Dynamic Response of MPPT and Droop-Controlled Microinverters
}

\author{
Ruben Barros Godoy, Member, IEEE, Douglas Buytendorp Bizarro, Student Member, IEEE, Elvey Tessaro de \\ Andrade, Member, IEEE, Jurandir de Oliveira Soares, Pedro Eugênio Marcondes Justino Ribeiro, \\ Leonardo A. Carniato, Marcio L. M. Kimpara, João O. P. Pinto, Senior Member, IEEE, \\ Kamal Al-Haddad, Fellow, IEEE, and Carlos Alberto Canesin, Senior Member, IEEE
}

\begin{abstract}
Due to the absence of communication needs and great reliability, the droop-control technique is a great choice for controlling of inverters that are subjected to load sharing or to work in an islanded mode. On the other hand, current-controlled inverters are often used in grid-connected systems due to their fast response to power the implementation of maximum power point tracking (MPPT) algorithms to maximize the power extracted from these systems. However, the application of such algorithms in gridconnected droop-controlled systems is hampered by differences in the dynamic responses of the respective techniques. In this context, this study presents the development of a strategy that enables a push-pull converter controlled by MPPT and a low-power plug and play grid-connected inverter governed by droop control to operate stably even under variations in solar radiation. The goal is achieved based on the following two approaches: designing the dclink capacitor properly and using a control loop in order to adapt the droop curves in accordance with the available input power. Theoretical analysis and experimental results have proven the viability of the approach.
\end{abstract}

Index Terms-Capacitor sizing, droop-controlled inverters, photovoltaic (PV) systems.

Manuscript received November 4, 2015; revised February 21, 2016, June 18 , 2016, and October 10, 2016; accepted November 18, 2016. Date of publication December 21, 2016; date of current version May 18, 2017. Paper 2015-SECSC0896.R3, presented at the 2015 IEEE Energy Conversion Congress and Exposition, Montreal, QC, Canada, September 20-24, and approved for publication in the IEEE TRANSACTIONS ON INDUSTRY APPLICATIONS by the Sustainable Energy Conversion Systems Committee of the IEEE Industry Application Society.

R. B. Godoy, E. T. de Andrade, J. de O. Soares, M. L. M. Kimpara, and J. O. P. Pinto are with the Electrical Engineering Department, Federal University of Mato Grosso do Sul, Campo Grande 79074460, Brazil (e-mail: ruben.ufms@gmail.com; elvey.br@gmail.com; jdeoliveirasoares@gmail.com; marcio.kimpara@gmail.com; joaonofre@gmail.com).

P. E. M. J. Ribeiro is with the Electrical Engineering Department, Federal University of Itajuba, Itajuba 37500-903, Brazil (e-mail: pedro. ribeiro@ silistecnologia.com.br).

L. A. Carniato is with the Sao Paulo Federal Institute of Education, Science and Technology, Presidente Epitacio 01109-010, Brazil (e-mail: leonardo@ ifsp.edu.br).

K. Al-Haddad is with the Electrical Engineering Department, École de technologie supérieure, Montreal, QC H3C 1K3, Canada (e-mail: kamal. al-haddad@etsmtl.ca).

D. B. Bizarro and C. A. Canesin is with the Faculdade de Engenharia de Ilha Solteira, Universidade Estadual Paulista, Ilha Solteira, Brazil 15385-000 (email: douglasbizarro@gmail.com; canesin@dee.feis.unesp.br).

Digital Object Identifier 10.1109/TIA.2016.2642883

\section{INTRODUCTION}

$\mathbf{E}$ NVIRONMENTAL, economical, and technological issues have stimulated the structuring of electrical systems according to the distributed generation (DG) model, which is related to small-scale power generation and composed mainly of renewable energy sources (RES). In the DG context, the concept of microgrid, which consists of the integration of local load and energy sources, has arisen. This closeness between load and generation tends to increase the reliability and quality of the delivered power.

For the development of a multimodal microgrid, comprised of different energy sources (driven by power electronic inverters) and local load, which is, furthermore, connected to the utility grid, the control technique that governs the inverters is a very important issue for reliable operation. From the analysis of the main techniques for inverters parallelism, Godoy et al. [1] highlights the use of methods that do not require interconnection between the control units, such as droop control, because of its stability and reliability.

Among the RES, the use of photovoltaic (PV) energy has grown exponentially in grid-connected systems [2], [3]. Some conventional grid-connected PV systems use current-controlled inverters to transfer power to the electrical grid [4]. This methodology is widely used when the inverter is connected to the utility grid (a stiff grid). However, the inverter output current can suffer abrupt variation in the matter of sudden change of the reference power. Besides, these techniques are not viable to the operation on islanded mode, or load sharing. Then, when a grid-connected inverter is subjected to an islanded mode operation, the control technique must be switched according to the operation mode (grid connected or off-grid) [5].

Droop control is an emerging technique applied to the parallel operation of off-grid voltage source inverters (VSI) [6]-[8]. The control strategy is based on emulating the features of a synchronous generator using a VSI. However, this technique is rarely exploited to control grid-connected inverters. The main usage of droop curves is on controlling and managing load sharing among parallel inverters connected to microgrids on the stand-alone mode [9]. Some works also use a dc voltage droop control to manage power flow on microgrid dc busses [10]-[13].

The hierarchical control presented in [5] proposes compensation in droop curve so that a microgrid, while in the 
stand-alone mode, could keep synchronized with the utility grid for an eventual reconnection and could operate in the connected mode. Nevertheless, all the inverters in this microgrid need to be interconnected by a communication network.

One drawback of droop control is its dynamic response. The dynamic of power transfer is slow due to the reduced bandwidth of the low-pass filter used to calculate the average active and reactive powers [14]. For near optimum responses, the best settling times achieved are around hundreds of milliseconds [1]. On the other hand, maximum power point tracking (MPPT) dynamic is considerably fast. Changes in climate conditions result in instantaneous changes in PV array output power, which are closely tracked by MPPT methods. Their convergence times are in the tens of milliseconds [15].

Therefore, the integration of these two techniques is obstructed by these intrinsic differences in the respective dynamics. Differences in the inherent dynamics of the two methods can result in operation being either at a point other than its maximum power, or in an unstable situation.

Recently, various studies have focused on the development of grid-connected PV systems [16]-[19]. Commonly, the MPPT is implemented through a dc-dc converter, by controlling the duty cycle. Nevertheless, Quamruzzaman et al. [19] proposes tracking the MPP directly by controlling the angle between the inverter and the grid voltage. However, for great variations in the generated power, this kind of control could yield quick shifts of the angle, damaging the inverter output voltage. This study presents only simulation results and does not consider large power variations. Other works [17], [18] propose the use of MPPT methods along with the droop control, but, again, the difference in the dynamics is not addressed and it is not clear how the association between the MPPT method and the droop control is reached.

In order to build a microgrid, where the inverters can be controlled by droop control curves either in stand-alone mode or grid-connected mode, Godoy et al. [1] has proposed choices for the slope of the curves that governs the power transfer through an evolutionary algorithm with the objective of optimizing the dynamic response. Complementarily, Carniato et al. [20] have used the evolutionary algorithm together with artificial neural networks to find the optimized parameters of the droop control curves for each possible operating point in order to ensure the stability as well as reduced settling time and damped response free of overshoot. Furthermore, Arafat et al. [6] proposed a transition controller strategy to perform transition between standalone operation mode and grid-connected operation mode, both using droop-control strategy.

The kind of microgrid proposed in [20] can handle multimodal energy sources and its inverters are controlled by the droop-control technique. The great advantage of using the droop control in grid-connected mode is that the inverters will always be controlled by a single control technique, switching only the control reference according to the operation mode.

In this context, in continuity to the work presented in [21], this paper presents the development of a strategy that enables a push-pull converter controlled by MPPT and a low-power plug and play grid-connected inverter governed by droop control to operate stably even under variations in solar radiation. That is, this paper is concerned specifically on matching MPPT and the droop-control technique during the grid-connected operation.

Considering that the proposed topology is intended to work in grid-connected mode and always track the maximum available power from the PV modules, the MPPT should be fast. Furthermore, in the case of sudden shading, regardless of the MPPT method, the generated power will instantly drop. In this situation, it is impossible to provide a soft variation in the angle without having energy storage, which would supply energy to the grid while the angle is being adjusted.

In this scenario, the implementation of a grid-connected PV system is proposed by associating the MPPT and droop-control techniques by means of a properly rated energy storage device, and by adding a feedforward control loop of the droop-curve parameters in such a way that it is possible to deal with the differences in the dynamics.

\section{PROPOSED SYSTEM}

The proposed system is capable of extracting the maximum available power from the panels and transferring it to the utility. The central idea incorporates a properly rated capacitor bank interfacing both converters and an additional control loop, comprised of a feedforward and feedback loops. The control loop is used to minimize the existing difference in dynamics; therefore, MPPT and droop control can be integrated even on occasions of sudden set-point variations. The dc-dc converter involves a three-level push-pull topology [22]. In addition to the MPPT function, this converter is also responsible for increasing the voltage from solar arrays.

To achieve the MPPT, the power processed by the $\mathrm{dc}-\mathrm{dc}$ converter needs to be sent to the utility grid by the inverter. However, in the traditional droop control, (1) describes the relation between the inverter output power and inverter frequency, where $\omega_{\text {inv }}$ is the inverter frequency, $\omega_{0}$ represents the inverter frequency at no load operation (where the droop curve crosses the $\omega$-axis), $P$ is the output power, and $k_{p}$ is the coefficient that determines the curve's slope. This means that at certain frequency, which is imposed by the utility grid, at a steady-state operation, the output power can be defined as

$$
\omega_{\text {inv }}=\omega_{0}-k_{p} P
$$

In order to track the MPP, the inverter output power needs to be dictated by the dc-dc converter, which actually is responsible for MPPT. To do so, (1) will be altered so that the inverter output power meets the dc-dc converter needs.

From (1), the term that represents the nonload frequency $\left(\omega_{0}\right)$ will be replaced by the sum of the grid frequency $\left(\omega_{g}\right)$ and the desired output power $\left(P_{\text {ref }}\right)$, while the output power will be represented as $P_{\text {meas }}$. Thus, in steady state, when the inverter frequency meets the grid frequency, the inverter output power ( $\left.P_{\text {meas }}\right)$ will be exactly equal to the reference power, according to the following equation:

$$
\omega_{\text {inv }}=\omega_{g}+k_{p} P_{\text {ref }}-k_{p} P_{\text {meas }} .
$$




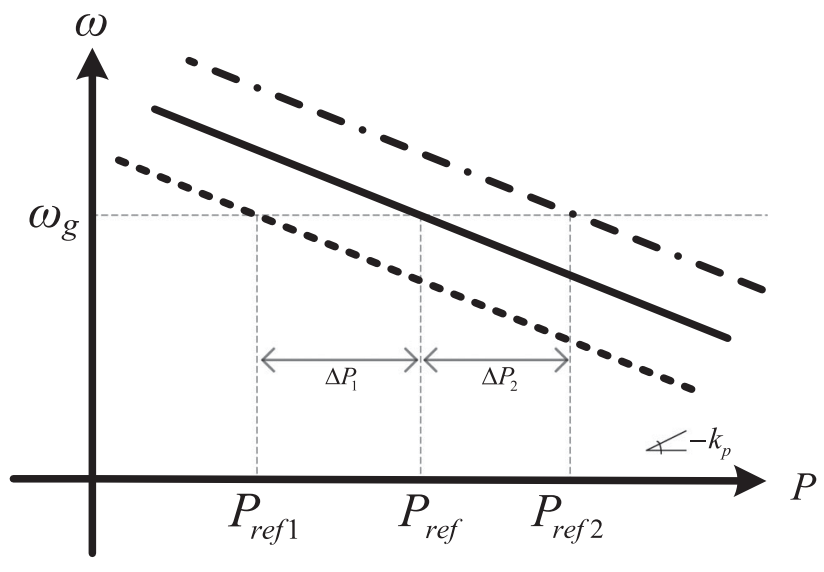

Fig. 1. Droop control curve.

By readjusting $P_{\text {ref }}$, the $P-\omega$ curve shifts vertically, as it can be seen in Fig. 1, where the dashed lines represent the new droop lines for $P_{\text {ref1 }}$ and $P_{\text {ref2 } 2}$. If the reference power $\left(P_{\text {ref }}\right)$ is changed, a new equilibrium point is set and the equilibrium frequency $\omega_{g}$, which is the grid frequency, remains the same. Considering that the goal of this equipment is to transfer the instantaneous power from PV modules, the reference power $\left(P_{\text {ref }}\right)$ must be replaced by the PV instantaneous power $\left(P_{\mathrm{MPPT}}\right)$. Assuming a system with no losses and that $P_{\mathrm{MPPT}}$ is instantaneously available at the inverter input, droop control will start acting in order to establish a new output power in accordance with the new reference. However, during this adjustment time, there is an imbalance between the $\mathrm{dc}-\mathrm{dc}$ converter output power and the inverter output power. Until the steadystate operation, either the surplus or the deficit of energy must be, respectively, stored or supplied by a storage device. That is why a dc-link capacitor is proposed to compensate this energy imbalance.

As a matter of consequence, after providing or storing energy, the dc-link voltage will change and its final value will depend on some variables, such as the chosen dc-link capacitance and the parameters of the droop control, as it will be depicted in Section IV.

Hence, a feedback controller is necessary to bring the dc-link voltage back to its reference value after a transient. Besides, since $P_{\mathrm{MPPT}}$ corresponds to the available power at the input of the whole system, by the time it reaches the output stage (droopcontrolled inverter), its value decreases due to the losses in the previous stage. Here, a controller is essential for compensating this power imbalance, so that it provides a fine tuning for the new power reference. Based on these facts, an additional control loop will be created so that the dc-link voltage also influences the droop curve. As it will be explained in Section V, a simple gain $\left(k_{v}\right)$ is enough to provide zero steady-state error. This way $P_{\text {ref }}$ from (2) is now composed of $P_{\mathrm{MPPT}}$ and the dclink voltage error, as represented in (3), where $\xi_{v}$ represents the difference between the dc-link instantaneous voltage and its reference voltage. Then, the droop curve is described as follows:

$$
\omega_{\mathrm{inv}}=\omega_{g}+k_{p}\left(P_{\mathrm{MPPT}}+k_{v} \xi_{V}\right)-k_{p} P_{\mathrm{meas}} .
$$

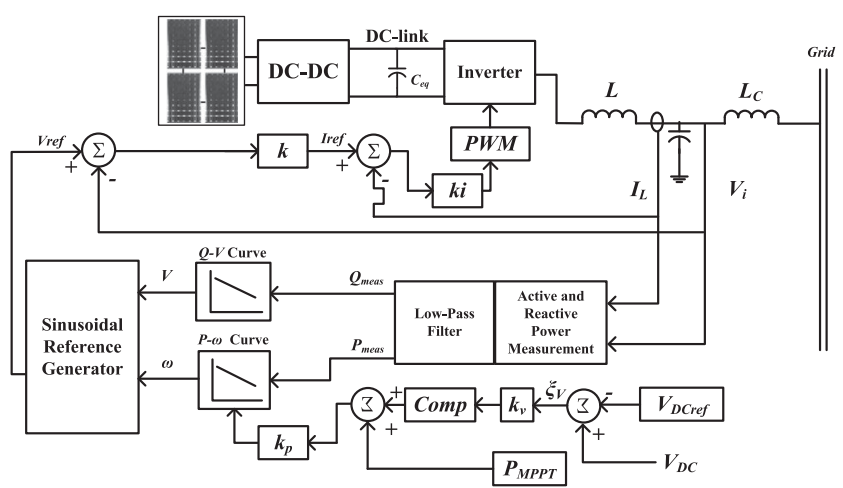

(a)

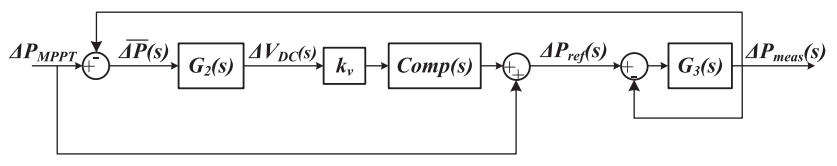

(b)

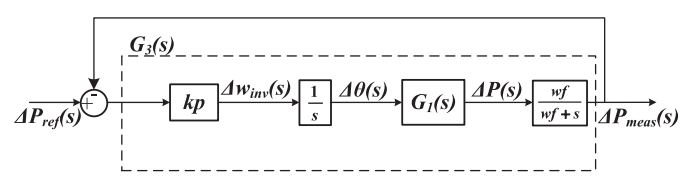

(c)

Fig. 2. (a) Proposed droop control system. (b) Block diagram. (c) Droop control plant.

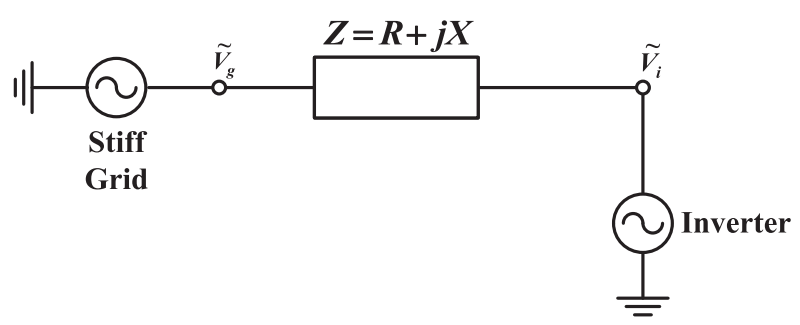

Fig. 3. Inverter connected to a stiff grid.

In order to improve the dynamic response of the system even more regarding the dc-link voltage, an additional controller was proposed (Comp), which is added in cascade with $k_{v}$. This controller is explained is Section V.

A system schematic can be seen in Fig. 2(a). The sinusoidal voltage amplitude and frequency references are generated by the drooping curves, and the $P-\omega$ curve is dynamically adjusted as proposed in Fig. 2(b) and (c).

\section{MODELING THE SYSTEM}

As it can be seen in Fig. 2(b), the block named $G_{2}(s)$ represents the plant of the dc-link capacitor voltage, and, in Fig. 2(c), the block named $G_{1}(s)$ represents the plant of the droop-controlled power inverter. First of all, in order to evaluate the dynamics of the droop control, $G_{1}(s)$ has to be modeled. Hence, the droop-controlled inverter is supposed to be connected to a stiff grid as presented in Fig. 3. The active power flow 
through the connection impedance is governed by the following equation, where $R$ and $X$ represent the connection impedance, $V_{g}$ represents the grid voltage, $V_{i}$ represents the inverter output voltage, and $\theta$ represents the angle between $V_{g}$ and $V_{i}$

$$
P=\frac{R V_{i}^{2}-R V_{g} V_{i} \cos (\theta)+X V_{g} V_{i} \sin (\theta)}{R^{2}+X^{2}} .
$$

Equation (4) can be linearized at a given point of operation, resulting in a linear relationship as presented in the following equations:

$$
\begin{aligned}
\Delta P & =K_{V} \cdot \Delta V_{i}+K_{\theta} \cdot \Delta \theta \\
K_{V} & =\frac{2 R V_{i}-R V_{g} \cos (\theta)+X V_{g} \sin (\theta)}{R^{2}+X^{2}} \\
K_{\theta} & =\frac{X V_{g} V_{i} \cos (\theta)+R V_{g} V_{i} \sin (\theta)}{R^{2}+X^{2}} .
\end{aligned}
$$

Finally, since (5) is linearized, the resulting measured linearized power after passing through the low-pass filter is represented in (8), where $\omega_{f}$ is the filter cutoff frequency

$$
\Delta P_{\text {meas }(s)}=\frac{\omega_{f}\left(K_{V} \cdot \Delta V_{i(s)}+K_{\theta} \cdot \Delta \theta_{(s)}\right)}{\omega_{f}+s} .
$$

Since no exchange of reactive power is supposed, $\Delta V_{\mathrm{i}}$ tends to be zero. Thus, $G_{1}(s)$ is reduced as presented in the following equation:

$$
G_{1(s)}=K_{\theta} .
$$

As it can be seen in Fig. 2(c), the droop control is a closedloop system. Assuming that $P_{\mathrm{MPPT}}$ is constant, the system can be reduced into the transfer function presented in the following equation:

$$
\frac{\Delta P_{\operatorname{meas}(s)}}{\Delta P_{\operatorname{ref}(s)}}=\frac{k_{p} \cdot K_{\theta}}{s+\left(\omega_{f}+k_{p} \cdot K_{\theta}\right)} .
$$

Subsequently, the transfer function for the dc-link voltage will be modeled considering the instantaneous power imbalance as the input of the system. Assuming that all the energy provided by the PV modules is instantly transferred to the dc-link with no losses, the capacitor voltage will increase or decrease depending on the quantity of energy delivered to the grid. Consequently, the voltage across the dc-Link will oscillate depending on the energy storage. Since the energy stored in the capacitor $\left(E_{c}\right)$ is calculated through (11), where $C$ is the capacitance and $V_{\mathrm{DC}}$ is the capacitor voltage, the linearized energy variation $\left(\Delta E_{c}\right)$ is represented as in (12)

$$
\begin{aligned}
E_{c} & =\frac{C V_{\mathrm{DC}}^{2}}{2} \\
\Delta E_{c} & =\Delta V_{\mathrm{DC}} \cdot C \cdot V_{\mathrm{DC}} .
\end{aligned}
$$

After deriving (12), voltage oscillations-to-power imbalance oscillations transfer function can be represented in (13), where $\overline{\Delta P}$ is the linearized power imbalance

$$
G_{2(s)}=\frac{\Delta V_{\mathrm{DC}(s)}}{\overline{\Delta P}_{(s)}}=\frac{1}{s C V_{\mathrm{DC}}} .
$$

\section{SIZING THE DC-LINK CAPACITOR}

Any variation in solar radiation causes an imbalance between the power generated by PV panels and the power absorbed by the utility grid. Consequently, as aforementioned in Section II, during a certain time interval, the difference between the input and the output powers results in a surplus or deficit of energy that is responsible for charging or discharging the dc-link capacitor. Assuming that there is not a controller to act on the dc-link voltage, the capacitor voltage will rise or drop until it stabilizes at a new equilibrium voltage.

Hence, in order to calculate the appropriate capacitor, it will be considered the maximum or minimum tolerable dc-link voltage after a transient (assuming the inexistence of a dc-link voltage controller). It is also worth recalling that the capacitor voltage oscillations are a matter of consequence of imbalances between the input power $\left(P_{\mathrm{MPPT}}\right)$ and the output power $\left(P_{\text {meas }}\right)$.

The imbalance time interval will depend on the droop dynamic. Thus, the dynamic of the droop control will be considered. According to Alves Coelho et al. [23], for an optimized droop-control system, the desirable power angle variation curve should be similar to a first-order system response; hence, the difference between the angle $\left(\theta_{(t)}\right)$ and the new equilibrium angle $\left(\theta_{e}\right)$ for a droop-optimized system can be described as in (14), where $k_{1}$ is a constant described by $\left(\theta_{(0)}-\theta_{e}\right)$ and $p_{1}$ is the dominant pole as described in [23]

$$
\theta_{(t)}=\theta_{e}+k_{1} e^{p_{1} t}
$$

Considering that for small angles $\sin (\theta)$ is approximately $\theta$, the dc-link output mean current $\left(i_{\text {out }}\right)$ can be calculated from the inverter output power, as described in (15). Hence, $i_{\text {out }}$ and the dc-link input current $\left(i_{\text {in }}\right)$ are determined as shown in (16) and (17). Consequently, the resulting capacitor current is obtained from the difference between (17) and (16), as shown in (18)

$$
\begin{gathered}
V_{\mathrm{DC}(t)} \cdot i_{\text {out }(t)}=P_{\text {meas }(t)}=\frac{V_{g}^{2} \cdot \theta_{(t)}}{X} \\
i_{\text {out }(t)}=\frac{V_{g}^{2} \cdot\left(\theta_{e}+k_{1} \cdot e^{p_{1} t}\right)}{X \cdot V_{\mathrm{DC}(t)}} \\
i_{\mathrm{in}(t)}=\frac{P_{\mathrm{MPPT}}}{V_{\mathrm{DC}(t)}} \\
C \cdot \frac{d V_{\mathrm{DC}(t)}}{d t}=i_{\mathrm{cap}(t)}=\frac{P_{\mathrm{MPPT}}}{V_{\mathrm{DC}(t)}}-\frac{V_{g}^{2} \cdot\left(\theta_{e}+k_{1} \cdot e^{p_{1} \cdot t}\right)}{X \cdot V_{\mathrm{DC}(t)}} .
\end{gathered}
$$

Rewriting (18) as (19) and integrating (19) over the time interval $t_{i}=0$ (instant of the disturbance occurrence) until $t_{f}=t_{e}$ (settling time), it results in (20)

$C \cdot V_{\mathrm{DC}(t)} \cdot d V_{\mathrm{DC}(t)}=\left(P_{\mathrm{MPPT}}-\frac{V_{g}^{2} \cdot\left(\theta_{e}+k_{1} \cdot e^{p_{1} \cdot t}\right)}{X}\right) d t$ 
TABLE I

DC-LINK SIZING PARAMETERS

\begin{tabular}{lc}
\hline \hline Parameter & Characteristics \\
\hline$V_{\mathrm{DC}(0)}$ & $380 \mathrm{~V}$ \\
$V_{\mathrm{DC}(\mathrm{te})}$ & $430 \mathrm{~V}$ \\
$V_{g}$ & $127 \mathrm{~V}_{\mathrm{rm} \mathrm{s}}$ \\
$L$ & $19 \mathrm{mH}$ \\
$k_{1}$ & $-0.1298 \mathrm{rad}$ \\
$k_{p(a)}$ & $1.9 \times 10^{-3}$ \\
$p_{1(a)}$ & -4.384 \\
$C_{(a)}$ & $3.3 \mathrm{mF}$ \\
$k_{p(b)}$ & $3.8 \times 10^{-3}$ \\
$p_{1(b)}$ & -9.093 \\
$C_{(b)}$ & $1.59 \mathrm{mF}$ \\
$k_{p(c)}$ & $7.6 \times 10^{-3}$ \\
$p_{1(c)}$ & -19.616 \\
$C_{(c)}$ & $736 \mu \mathrm{F}$ \\
\hline \hline
\end{tabular}

$$
\begin{gathered}
C \frac{V_{\mathrm{DC}\left(t_{e}\right)}^{2}-V_{\mathrm{DC}(0)}^{2}}{2}=P_{\mathrm{MPPT}} \cdot t_{e}-\frac{V_{g}^{2} \cdot \theta_{e} \cdot t_{e}}{X} \ldots \\
-\frac{V_{g}^{2} \cdot k_{1} \cdot e^{p_{1} \cdot t_{e}}}{X \cdot p_{1}}+\frac{V_{g}^{2} \cdot k_{1}}{X \cdot p_{1}} .
\end{gathered}
$$

At the instant $t_{\mathrm{e}}$, the power transmitted to the grid $\left(V_{g}^{2} \cdot \theta_{e} / X\right)$ is equal to the power requested from the panel $\left(P_{\mathrm{MPPT}}\right)$. Besides, $e^{p_{1} t_{\varepsilon}} \approx 0$, then (20) can finally be written as

$$
C=\left(\frac{2}{V_{\mathrm{DC}\left(t_{e}\right)^{2}}-V_{\mathrm{DC}(0)}{ }^{2}}\right) \cdot\left(\frac{V_{g}^{2} \cdot k_{1}}{X \cdot p_{1}}\right) .
$$

\section{A. Sizing Method Validation}

In order to validate the proposed method to size the dc-link capacitor, three simulations, with different droop dynamics, which will be called Simulation (a), Simulation (b), and Simulation (c), were performed, considering three different slops of the droop active power versus frequency curve $\left(k_{p(a)}, k_{p(b)}\right.$ and $\left.k_{p(c)}\right)$. In both simulations, the system was subjected to an input power variation, corresponding to a step from 160 to $450 \mathrm{~W}$ at time $t=5 \mathrm{~s}$. The goal is to find the required dc-link capacitance for each simulation so that the dc-link voltage after the transient be the same in all the three cases.

It is worth mentioning that the power angle $\left(\theta_{(t)}\right)$ is related to the power injected in the grid; hence, the difference between the initial angle and the angle after the transient $\left(k_{1}\right)$ is the same at all the three simulations.

As described in Table I, the reference dc-link voltage $\left(V_{\mathrm{DC}(0)}\right)$, the maximum desired dc-link voltage after the transient $\left(V_{\mathrm{DC}(\mathrm{te})}\right)$, the connection impedance $(X=120 \pi \cdot \mathrm{L})$ and the grid rms voltage $\left(V_{g}\right)$ are the same for both simulations. However, each simulation presents a different value of the droop curve slope, as can be seen in the same table. Hence, the droopcontrol dynamic is different for each case. This difference can be noticed through Fig. 4, which shows the power angle settling curve for each simulation. It can be noticed that the dotted curve, from Simulation (a), which has the lowest slope, is the one with the slowest dynamic response. On the other hand, the

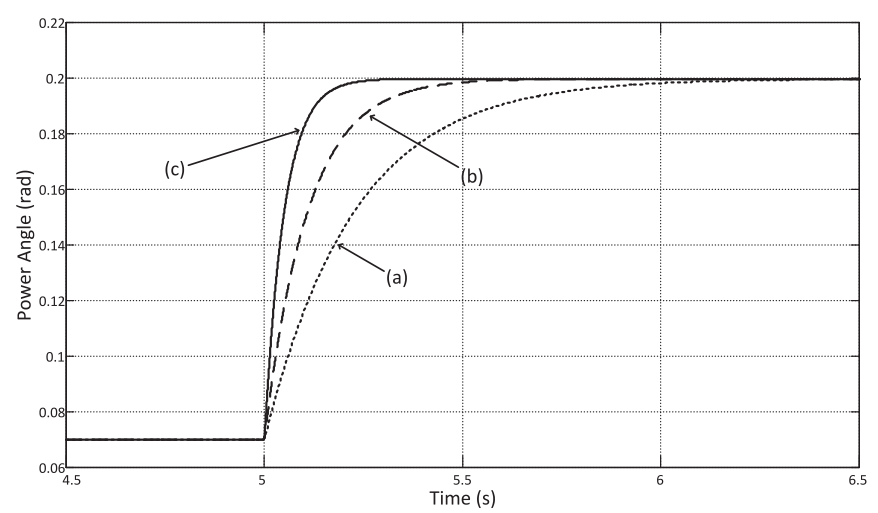

Fig. 4. Power angle settling curves for Simulations (a), (b), and (c).

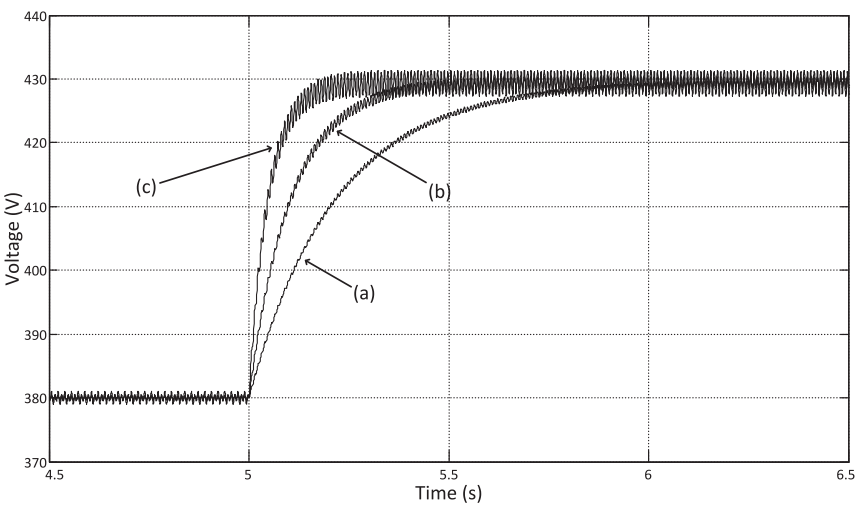

Fig. 5. DC-link voltage settling curves for Simulations (a), (b), and (c).

continuous curve, from Simulation (c), is the one with the fastest dynamic response.

As described in Section II, when there is a step in the input power, there is a surplus of energy stored in the capacitor, which leads to the increase in dc-link voltage. As described in the beginning of this section, the dc-link voltage control loop was not considered during the calculations. Hence, the feedback control loop was disabled in the simulations, maintaining only the feedforward loop. Therefore, after the transient, the dc-link voltage will stabilize on voltage $V_{\mathrm{DC}(\mathrm{te})}$, as given in Table I.

From the curves presented in Fig. 4, the dominant pole $\left(p_{1}\right)$ for each simulation was found, as seen in Table I. Then, using (21), the necessary capacitance for each simulation (in order to achieve voltage $V_{\mathrm{DC}(\mathrm{te})}$ ) was calculated. These capacitances are also presented in Table I.

It can be noticed that, since Simulation (c) has the fastest droop curve (highest slope), the inverter output power in this simulation will rapidly achieve the value of the system input power after the transient; hence, the capacitance in this simulation can be smaller than the capacitance in the other simulations.

Finally, Fig. 5 presents the dc-link voltage settling curve for each simulation considering the capacitances listed in Table I. It can be noticed that in all simulations, the final value of the dc-link voltage was $430 \mathrm{~V}$, exactly the same desired value. This shows the effectiveness of (21). It can also be noticed that due to 
lower capacitance, the $120 \mathrm{~Hz}$ oscillations of the dc-link voltage are higher in Simulation (c).

\section{VOLTAGE CONTROLler}

In order to maintain the dc-Link voltage constant, a controller was proposed as presented in Fig. 2(a) and (b). Without a controller, the dc-link voltage can remain steady in inappropriate voltage values, e.g., after a reduction on solar irradiation, the voltage on the capacitor could go below $180 \mathrm{~V}$ and derail the inverter modulation. The challenge is to choose the controller and tune the appropriate constants to reach a good dynamic response.

Considering that $P_{\mathrm{MPPT}}$ is constant, the open-loop transfer function for voltage variations-to-reference power oscillations is shown as follows:

$$
\frac{\Delta V_{\mathrm{DC}}(s)}{\Delta P_{\mathrm{ref}(s)}}=\frac{-k_{p} K_{\theta}}{C V_{\mathrm{DC}}} \cdot \frac{1}{s\left(s+\left(\omega_{f}+k_{p} K_{\theta}\right)\right)} .
$$

Looking at (22), it is reasonable to suggest a simple proportional controller to compensate the dc-Link voltage oscillations. However, the challenge is to deal with $K_{\theta}$ since, depending on the operating point, it will change the second pole position. In order to cancel down the nonzero pole, the compensator must be implemented with a zero positioned a little before $\omega_{f}$ (by tuning $\left.k_{t}\right)$, and a gain $\left(k_{\mathrm{c}}\right)$ to set the appropriate cutoff frequency. The compensator transfer function is presented as follows:

$$
\operatorname{Comp}_{(s)}=k_{c}\left(s+k_{t} \omega_{f}\right) \text {. }
$$

In practice, it is not simple to implement a derivative compensator. Hence, in order to dispense the implementation of this compensator, the $k_{p}$ constant was tuned in such a way to meet two main requirements: first, setting the droop curve in order to obtain a first-order response with the shortest possible settling time during the power transfer [24] and, second, finding a value for $k_{p}$ that is small enough in order to guarantee that the system cutoff frequency will nullify the second pole effect, presented in (21).

\section{Simulation RESUlts}

In order to verify the performance of the proposed control methodology, a simulation of the complete system was performed using the MATLAB/Simulink software. The push-pull converter was controlled by the MPPT algorithm PI-P\&O [25], the same used at the experimental results, and the VSI used the droop curves to control the connection to the electrical grid.

First, the electrical characteristics of a solar panel were considered for two different solar irradiation levels, represented by the two extreme cases presented in Table III. Hence, in order to evaluate the system's behavior under extreme conditions regarding the dynamic performance, the system was analyzed for step transitions between irradiation levels of 400 and $1000 \mathrm{~W} / \mathrm{m}^{2}$.

With the decrease in solar radiation, from 1000 to $400 \mathrm{~W} / \mathrm{m}^{2}$, there is an instantaneous reduction in the power generated by the panel, as depicted in Fig. 6 (at time 5 s), where the continuous line represents the PV panel output power and the dashed line represents the inverter output power. Because the dynamic

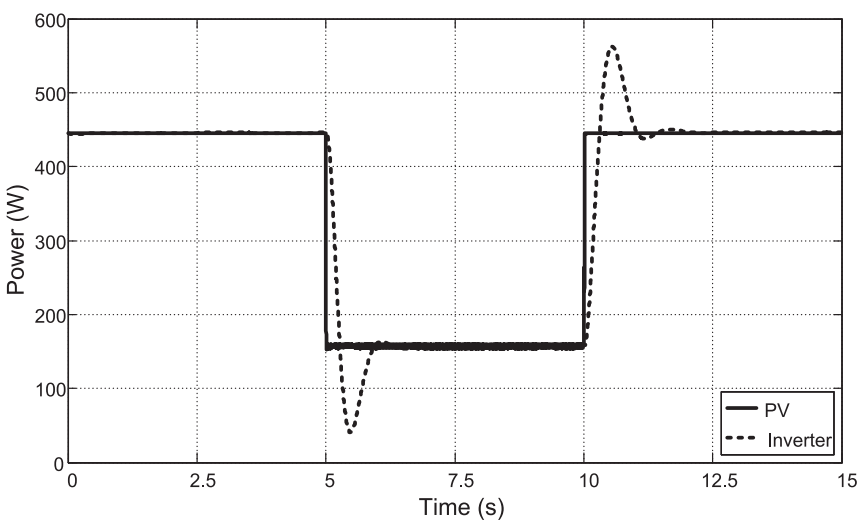

Fig. 6. PV panel power and inverter output power.

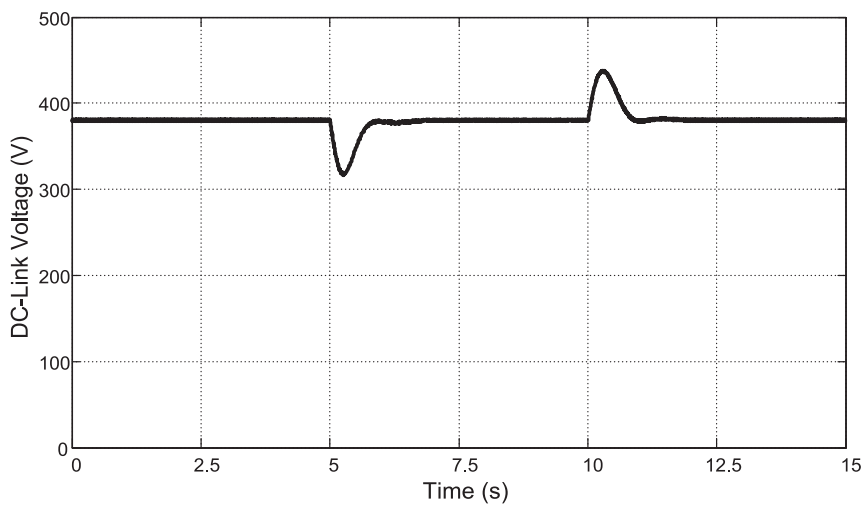

Fig. 7. DC-link voltage.

of the MPPT algorithm is significantly faster than the dynamic of the droop control, the power transfer from the PV panel to the capacitor (dc link) is instantly reduced; however, the power transfer from the capacitor to the grid is not instantaneously altered, as shown by the dashed line in Fig. 6. This phenomenon causes a momentary decrease in the energy stored in the capacitor and thus interferes with the voltage over the capacitor. Therefore, the output voltage of the push-pull converter, which is configured to be maintained at $380 \mathrm{~V}$ at steady state, suffers an immediate drop, as shown in Fig. 7 (at time 5 s). During this transient, the amplitude of the inverter output current exhibits oscillations, which are proportional to the inverter output power oscillations, until a new inverter set-point is established by the droop control, resulting in a decrease in the power sent to the grid and stabilization of the dc-link voltage. The inverter output current during the first transient is presented in Fig. 8.

The opposite effect occurs, following a sudden increase in solar radiation, from to $1000 \mathrm{~W} / \mathrm{m}^{2}$, according to the second transient, at time $10 \mathrm{~s}$ in Figs. 6 and 7. The power from the panel increases rapidly, whereas the inverter output power increases in a slower pace. Thus, the voltage over the capacitor increases due to the imbalance between the power produced by the solar panel and the power sent to the electrical grid. Analogously, the amplitude of the inverter's output current oscillates until the droop control finds new set-point for power transfer from the dc-link capacitor to the electrical grid. 


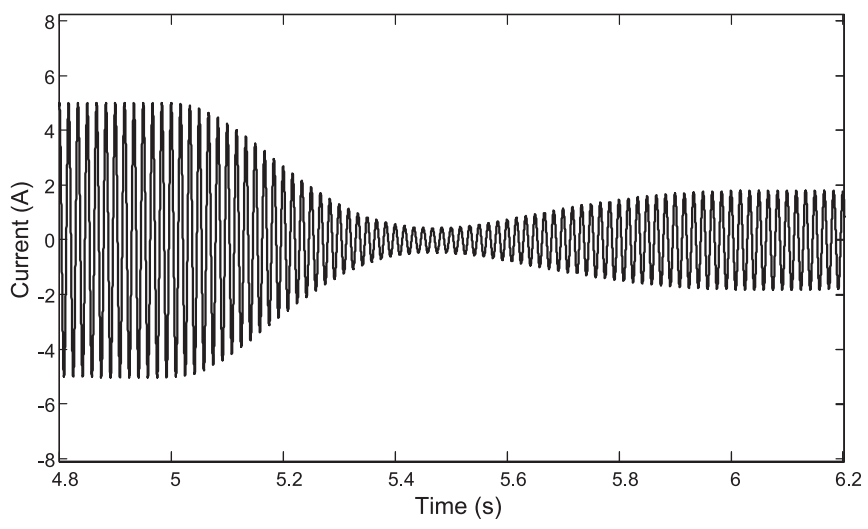

Fig. 8. Inverter output current.

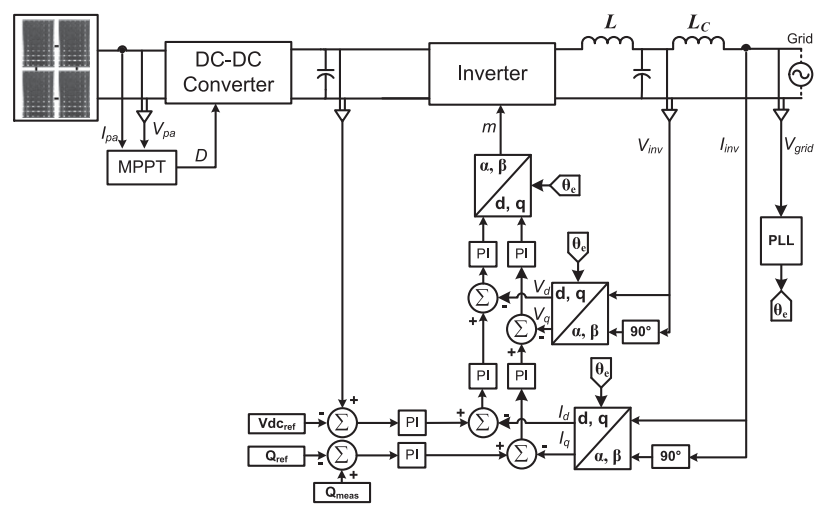

Fig. 9. Block diagram of the conventional current control.

It is important to notice that there must be an overshoot on the output power waveform, so that, in the irradiation reduction transient, the inverter output power is lower than the PV panel power during certain time, in order to let the dc-link voltage return to its reference value. This overshoot is clearly seen in Fig. 6 for both irradiation decrease and irradiation increase transients. This overshoot occurs due to the action of the feedback control loop.

In Figss. 6-8, it is shown that although the droop-control dynamics is slower than the MPPT dynamics, the performance is good enough in order to allow these two techniques to work together.

\section{COMPARISON BETWEEN DROOP CONTROL AND CURRENT CONTROL}

This section was proposed exclusively to investigate how appropriate the proposed method is in comparison with a stateof-the-art technique. It is well known that the current control in grid-tie applications is a reference method regarding its fast dynamic performance [26]. Thus, as a matter of comparison, an equivalent system, controlled by the conventional current control, was simulated and subjected to exactly the same solar irradiation variation performed in Section VI. Fig. 9 presents the block diagram of the implemented current-control technique. This figure makes the amount of cascaded PI compensators evident that must be tuned.

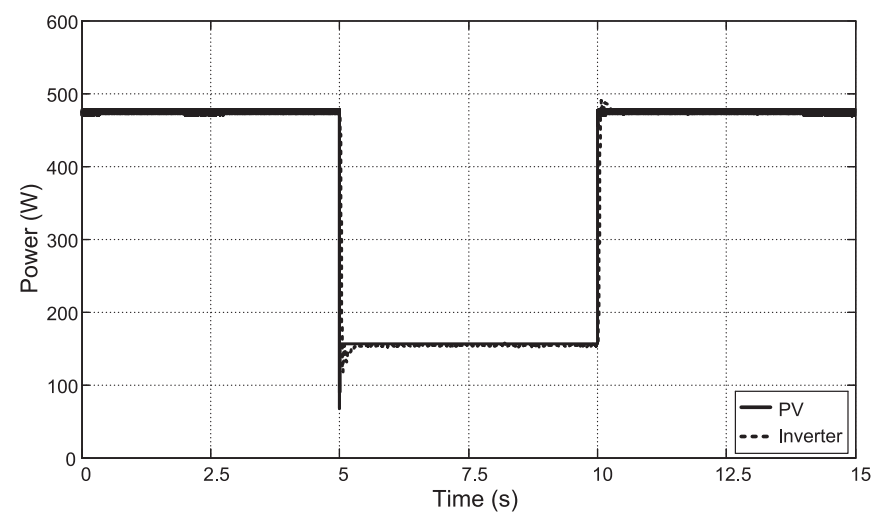

Fig. 10. PV panel power and inverter output power for current control.

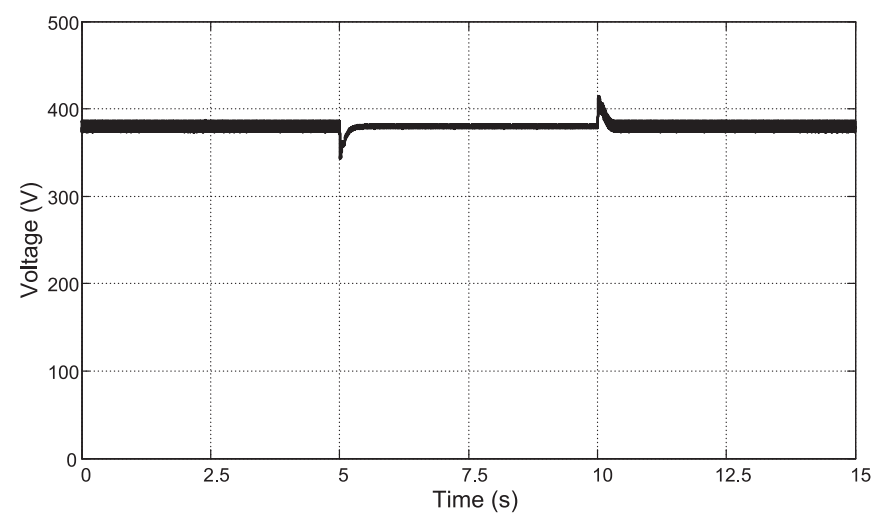

Fig. 11. DC-link voltage for current control.

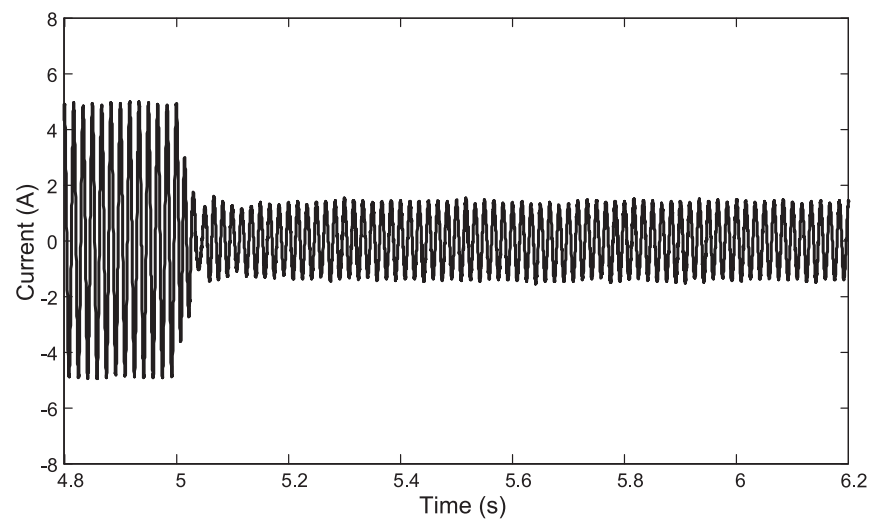

Fig. 12. Inverter output current for current control.

Figs. 10-12 are equivalent to Figs. 6-8, respectively; however, they describe the performance of the current control technique.

The results presented in Figs. 10-12 make it noticeable that the dynamic response of the current control is really fast. On the other hand, it is worth mentioning that the good performance of this method relies on a difficult simultaneous tuning of the PI compensators presented in Fig. 9. And this tuning is also very sensitive to parameter variations, e.g., if the grid nominal voltage is altered, the compensators need to be tuned again.

As depicted in Figs. 7, 8, 11, and 12, the droop-control dynamic response is not as fast as the current control dynamic 
TABLE II

CIRCUIT COMPONENTS DATA

\begin{tabular}{lc}
\hline \hline Parameter & Characteristics \\
\hline Push-pull input voltage & $60 \mathrm{~V}_{\mathrm{D} \mathrm{C}}$ \\
Push-pull output voltage & $400 \mathrm{~V}_{\mathrm{D} \mathrm{C}}$ \\
Push-pull switching frequency & $50 \mathrm{kHz}$ \\
Inverter input capacitance $(C)$ & $810 \mu \mathrm{F} / 800 \mathrm{~V}$ \\
Grid-connection inductor $(L)$ & $19 \mathrm{mH} / 5 \mathrm{~A}$ \\
\hline \hline
\end{tabular}

TABLE III

SOLAR PANEL PARAMETERS

\begin{tabular}{lcccc}
\hline \hline Case & $\begin{array}{c}\text { Insolation } \\
\text { in W/m² }\end{array}$ & $\begin{array}{c}\text { Maximum } \\
\text { power }\end{array}$ & $\begin{array}{c}\text { Voltage at } \\
\text { maximum power }\end{array}$ & $\begin{array}{c}\text { Current at } \\
\text { maximum power }\end{array}$ \\
\hline 1 & 1000 & $452.4 \mathrm{~W}$ & $58 \mathrm{~V}$ & $7.8 \mathrm{~A}$ \\
2 & 750 & $319.0 \mathrm{~W}$ & $58 \mathrm{~V}$ & $5.5 \mathrm{~A}$ \\
3 & 400 & $174.0 \mathrm{~W}$ & $58 \mathrm{~V}$ & $3.0 \mathrm{~A}$ \\
\hline \hline
\end{tabular}

response. However, the benefits provided by the droop control, such as ease of implementation, absence of communication needs, robustness to parameter variations, and behavior as a voltage source, can be used to their fullest extent, provided that it is optimized according to [1]. As a matter of fact, it can provide acceptable performance in order to operate together with MPPT, as it can be seen in Figs. 7 and 8 and also confirmed by the experimentations in [21]. Still comparing Figs. 7 and 8 to Figs. 10 and 11, it can be seen that the steady state in both methods are fairly similar. As expected, the difference lies on the slower settling time in the droop control. Taking into account that the droop control was properly optimized, the results confirm stability and safe operation together with MPPT. Other important feature is that there is no waste of energy, since any temporary surplus or deficit of energy is, respectively, absorbed or supplied by the dc-link capacitor, without any risk of damage due to the voltage variations indeed.

\section{EXPERIMENTAL RESULTS}

An experimental setup of the topology was assembled using the parts available in the laboratory, regardless of any power correspondence among them. The main parameters of the converters are listed in Table II. To provide energy for the system, a solar array simulator (SAS) E4350B (Agilent Technologies) was used [27].

Two different tests were performed, each with a specific power profile programmed into the SAS. The electrical characteristics of a solar panel were considered for three different solar radiations and they are shown in Table III. It is noteworthy that this paper is mainly focused on reducing the dc-link capacitance through an appropriate matching of MPPT technique and droop controller. That is why, time was not spent on maximizing both conversion efficiency and tracking efficiency. The following experimentations show the controller performance toward radiance variations.

The tests were defined in the following manner.

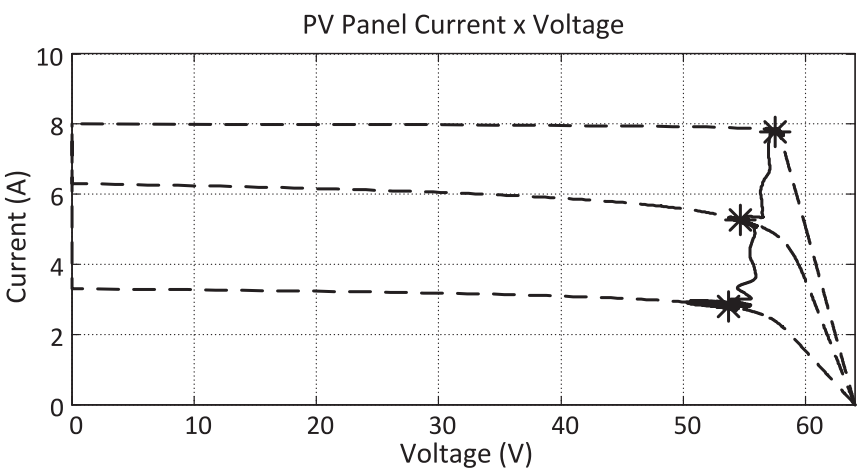

Fig. 13. Performance of the MPPT method for the three $V \times I$ curves in the first test.

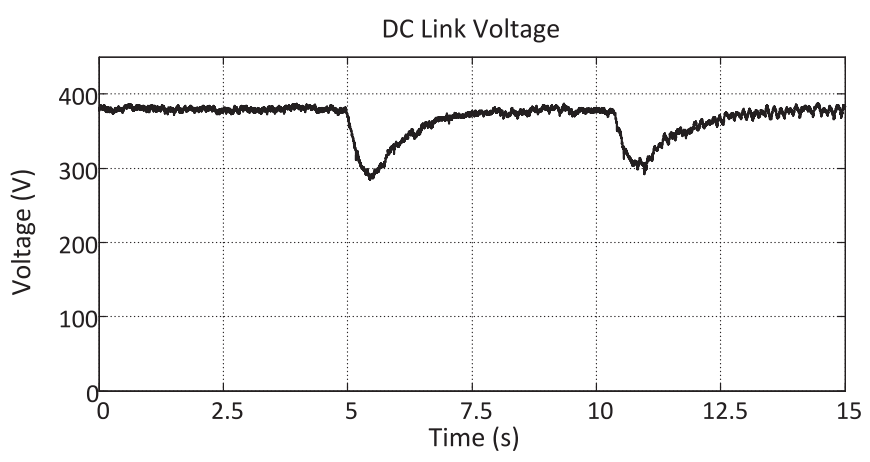

Fig. 14. Voltage in the dc-link during the first test.

First test: Reduction from the maximum radiation (maximum power) to the minimum radiation (minimum power) in three small steps.

Second test: Instantaneous transition from the maximum solar radiation to the minimum solar radiation, and instantaneous transition from minimum solar radiation to the maximum solar radiation.

The dashed curves shown in Fig. 13 were generated by the SAS and were used in the tests previously quoted. The points marked by asterisks represent the maximum power points of each curve, and the continuous lines that connect these points indicate the form by which the MPPT algorithm acts based on the variation in the solar radiation. The output voltage of the push-pull (dc link) is verified in Fig. 14.

It is worth mentioning that while the drop in the power generated by the panel is nearly instantaneous, the adjustment in the power transferred to the grid is significantly slower. The slowness is due to droop-control dynamics. In this situation, the panel is already operating at a lower power state, whereas the inverter is still adjusting its new power angle, and, therefore, it is sending more power to the electrical grid than the steadystate power expected for this new radiation condition. Due to this deficit, the dc-link voltage drops suddenly (undershoot), as shown in Fig. 14. After the control algorithm adjusts the inverter's new set-point, the dc-link voltage returns to its normal operating value.

The second test performance is noticed in Fig. 15. With the abrupt reduction in radiation from 1000 to $400 \mathrm{~W} / \mathrm{m}^{2}$, the power 


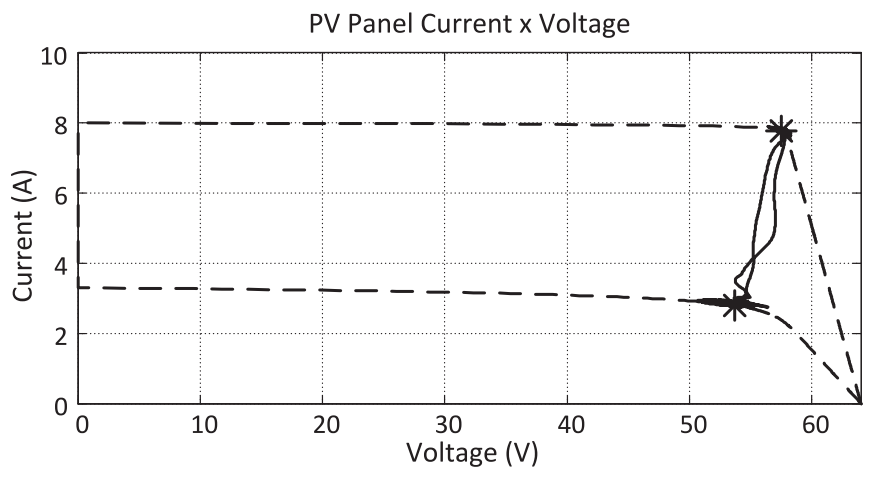

Fig. 15. Performance of the MPPT method for the two $V \times I$ curves in the second test.

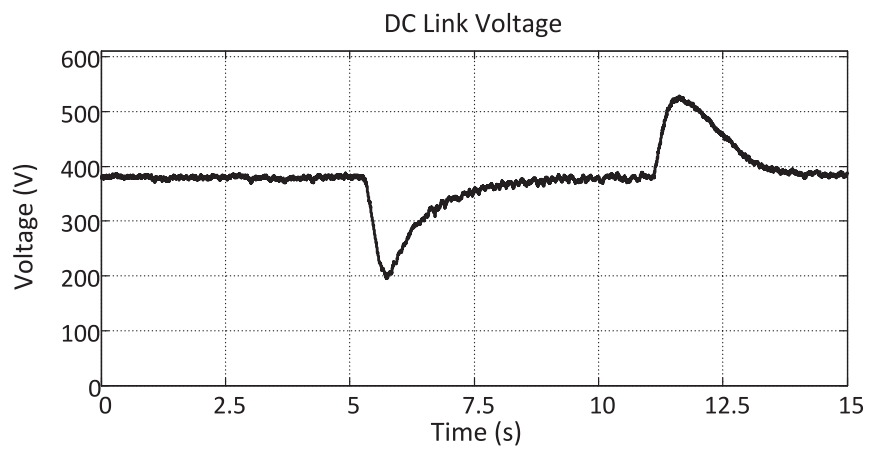

Fig. 16. Voltage in the dc-link during the second test.

generated was also reduced in a very short period of time. The droop-control dynamics imposes a relatively slow adjustment in the power injected into the grid and consequently a momentary energy imbalance results in transients in the dc-link voltage. Therefore, a significant drop in the output voltage of the pushpull converter is observed (see Fig. 16) during the first power transition. However, the minimum value of voltage in the dc-link must be maintained above $200 \mathrm{~V}$, which is needed to maintain the inverter operation. It indeed proves that the capacitor sizing proposed in this paper was effective.

\section{CONCLUSION}

This paper evaluated a way to size a dc-link capacitor to act as a momentary energy storage to make possible the matching between the fast dynamic of MPPT and the slow dynamic of droop control. The proposed system was connected to grid utility in order to transfer all the energy produced by an SAS.

In order to reach an effective control over the capacitor voltage, two things were evaluated: the first one was to establish a method to size the dc-link capacitor, since during transients the use of inadequate values can lead the system to either destructive or nonoperating voltages. The second one was to tune an adequate response to slowly return the dc-link voltage to its normal operating value without interfering with the droop-control dynamic.

In general, obtained results showed a good performance. In fact, as explained during the work, the droop-control technique is not as fast as the conventional current control technique, which was presented in Section VII. However, droop control presents lots of other benefits, like ease of project and implementation, absence of communication needs, great reliability, and capability of operating on islanded mode. Currently, the converter is being optimized to meet commercial requirements. The final product is going to be used in plug and play PV microinverters.

\section{REFERENCES}

[1] R. B. Godoy, J. O. P. Pinto, C. A. Canesin, E. A. Alves Coelho, and A. M. A. C. Pinto, "Differential-evolution-based optimization of the dynamic response for parallel operation of inverters with no controller interconnection," IEEE Trans. Ind. Electron., vol. 59, no. 7, pp. 2859-2866, Jul. 2012.

[2] J. Hu, J. Zhu, and D. G. Dorrell, "Model predictive control of gridconnected inverters for PV systems with flexible power regulation and switching frequency reduction," IEEE Trans. Ind. Appl., vol. 51, no. 1, pp. 587-594, Jan./Feb. 2015.

[3] M. A. G. de Brito, L. Galotto, L. P. Sampaio, G. de Azevedo e Melo, and C. A. Canesin, "Evaluation of the main MPPT techniques for photovoltaic applications," IEEE Trans. Ind. Electron., vol. 60, no. 3, pp. 1156-1167, Mar. 2013.

[4] S. B. Kjaer, J. K. Pedersen, and F. Blaabjerg, "A review of singlephase grid-connected inverters for photovoltaic modules," IEEE Trans. Ind. Appl., vol. 41, no. 5, pp. 1292-1306, Sep./Oct. 2005.

[5] J. M. Guerrero, J. C. Vasquez, J. Matas, L. G. de Vicuña, and M. Castilla, "Hierarchical control of droop-controlled AC and DC microgrids-A general approach toward standardization," IEEE Trans. Ind. Electron., vol. 58, no. 1, pp. 158-172, Jan. 2011.

[6] M. N. Arafat, A. Elrayyah, and Y. Sozer, "An effective smooth transition control strategy using droop-based synchronization for parallel inverters," IEEE Trans. Ind. Appl., vol. 51, no. 3, pp. 2443-2454, May/Jun. 2015.

[7] C.-T. Lee, R.-P. Jiang, and P.-T. Cheng, "A grid synchronization method for droop-controlled distributed energy resource converters," IEEE Trans. Ind. Appl., vol. 49, no. 2, pp. 954-962, Mar./Apr. 2013.

[8] M. C. Chandorkar, D. M. Divan, and R. Adapa, "Control of parallel connected inverters in standalone AC supply systems," IEEE Trans. Ind. Appl., vol. 29, no. 1, pp. 136-143, Jan./Feb. 1993.

[9] A. Elrayyah, F. Cingoz, and Y. Sozer, "Construction of nonlinear droop relations to optimize islanded microgrid operation," IEEE Trans. Ind. Appl., vol. 51, no. 4, pp. 3404-3413, Jul./Aug. 2015.

[10] K. Rouzbehi, A. Miranian, J. I. Candela, A. Luna, and P. Rodriguez, "A generalized voltage droop strategy for control of multiterminal DC grids," IEEE Trans. Ind. Appl., vol. 51, no. 1, pp. 607-618, Jan./Feb. 2015.

[11] A. Maknouninejad, Z. Qu, F. L. Lewis, and A. Davoudi, "Optimal, nonlinear, and distributed designs of droop controls for DC microgrids," IEEE Trans. Smart Grid, vol. 5, no. 5, pp. 2508-2516, Sep. 2014.

[12] R. Eriksson, J. Beerten, M. Ghandhari, and R. Belmans, "Optimizing DC voltage droop settings for AC/DC system interactions," IEEE Trans. Power Del., vol. 29, no. 1, pp. 362-369, Feb. 2014.

[13] C. Gavriluta, J. I. Candela, C. Citro, J. Rocabert, A. Luna, and P. Rodriguez, "Decentralized primary control of MTDC networks with energy storage and distributed generation," IEEE Trans. Ind. Appl., vol. 50, no. 6, pp. 4122-4131, Nov./Dec. 2014.

[14] X. Lu, K. Sun, J. M. Guerrero, J. C. Vasquez, and L. Huang, "Stateof-charge balance using adaptive droop control for distributed energy storage systems in DC microgrid applications," IEEE Trans. Ind. Electron., vol. 61, no. 6, pp. 2804-2815, Jun. 2014.

[15] T. Esram and P. L. Chapman, "Comparison of photovoltaic array maximum power point tracking techniques," IEEE Trans. Energy Convers., vol. 22, no. 2, pp. 439-449, Jun. 2007.

[16] T. Dragicevic, J. M. Guerrero, J. C. Vasquez, and D. Skrlec, "Supervisory control of an adaptive-droop regulated DC microgrid with battery management capability," IEEE Trans. Power Electron., vol. 29, no. 2, pp. 695-706, Feb. 2014.

[17] J. C. Vasquez, R. A. Mastromauro, J. M. Guerrero, and M. Liserre, "Voltage support provided by a droop-controlled multifunctional inverter," IEEE Trans. Ind. Electron., vol. 56, no. 11, pp. 4510-4519, Nov. 2009.

[18] H. Bevrani and S. Shokoohi, "An intelligent droop control for simultaneous voltage and frequency regulation in islanded microgrids," IEEE Trans. Smart Grid, vol. 4, no. 3, pp. 1505-1513, Sep. 2013.

[19] M. Quamruzzaman and K. M. Rahman, "Development of a new phaseangle controlled grid-connected PV system," in Proc. 2010 Int. Conf. Elect. Comput. Eng., Dec. 2010, pp. 82-85. 
[20] L. A. Carniato, R. B. Godoy, J. O. P. Pinto, C. A. Canesin, and P. E. M. J. Ribeiro, "Dynamic adaptation of droop control curves for microgrid connected inverters with variable input power," in Proc. 2013 Brazilian Power Electron. Conf., Oct. 2013, pp. 1022-1028.

[21] R. B. Godoy et al., "Procedure to match the dynamic response of MPPT and droop-controlled microinverters," in Proc.2015 IEEE Energy Convers. Congr. Expo., Sep. 2015, pp. 4188-4193.

[22] R. B. Godoy et al., "Design and implementation of a utility interactive converter for small distributed generation," in Proc. 41st IAS Anпи. Meet. Conf. Rec. 2006 IEEE Ind. Appl. Conf., Oct. 2006, vol. 2, pp. 1032-1038.

[23] E. A. Alves Coelho, P. C. Cortizo, and P. F. D. Garcia, "Small signal stability for single phase inverter connected to stiff AC system," in Proc. 34th IAS Annu. Meet. Conf. Rec. 1999 IEEE Ind. Appl. Conf., 1999, vol. 4, pp. 2180-2187.

[24] Z. Chen, X. Pei, W. Zhu, X. Liu, and L. Peng, "A two-stage combined control strategy for parallel operation of inverter," in Proc. 2015 IEEE Energy Convers. Congr. Expo., Sep. 2015, pp. 4582-4587.

[25] A. K. Abdelsalam, A. M. Massoud, S. Ahmed, and P. Enjeti, "High-performance adaptive perturb and observe MPPT technique for photovoltaic-based microgrids," IEEE Trans. Power Electron., vol. 26, no. 4, pp. 1010-1021, Apr. 2011.

[26] B. Bahrani, A. Rufer, S. Kenzelmann, and L. Lopes, "Vector control of single-phase voltage-source converters based on fictive-axis emulation," IEEE Trans. Ind. Appl., vol. 47, no. 2, pp. 831-840, Mar./Apr. 2011.

[27] "Operating guide for solar array simulator agilent models E4350B, E4351B," Agilent Technologies, Bayan Lepas, Malaysia, Sep. 2004.

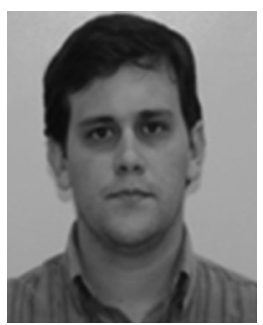

Ruben Barros Godoy (M'10) was born in Campo Grande, Brazil. He received the B.S. and M.S. degrees in electrical engineering from the Federal University of Mato Grosso do Sul, Campo Grande, Brazil, in 2004 and 2006, respectively, and the Ph.D. degree in electrical engineering from São Paulo State University, Ilha Solteira, Brazil, in 2010.

He currently holds a faculty position at the Federal University of Mato Grosso do Sul. His main publications are related in power electronics and artificial intelligence. His research interests include parallel inverters, microinverters, and emergency water pumping systems.

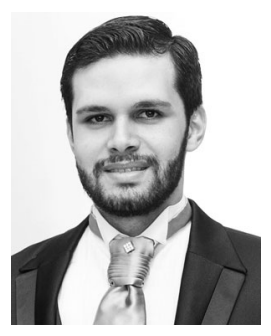

Douglas Buytendorp Bizarro ( $\mathrm{S}^{\prime}$ '15) was born in Campo Grande, Brazil, in 1990. He received the B.S. and M.S. degrees in electrical engineering from the Federal University of Mato Grosso do Sul (UFMS), Campo Grande, Brazil, in 2012 and 2015, respectively. He is currently working toward the Ph.D. degree in electrical engineering in the Faculdade de Engenharia de Ilha Solteira, São Paulo State University, Ilha Solteira, Brazil.

His current research focuses on photovoltaic systems.

Dr. Bizarro was a member of the UFMS team, during graduation, that competed on the 2011 IEEE International Future Energy Challenge, and won the IES Innovative Design of Power Electronic Converters Award.

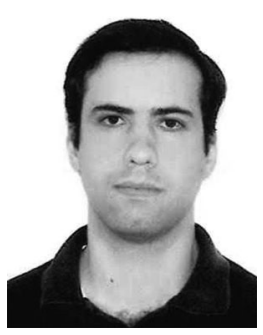

Elvey Tessaro de Andrade (M'13) was born in Campo Grande, Brazil. He received the B.S and M.S. degrees in electrical engineering from the Federal University of Mato Grosso do Sul (UFMS), Campo Grande, Brazil, in 2009 and 2013, respectively.

From 2012 to 2014 , he was a faculty member at the UFMS. He is currently a Researcher in the BATLAB, UFMS, and an Analyst in electrical engineering in the Brazilian Public Prosecutor's Office. His research interests include power electronics, signal processing and artificial intelligence, energy conversion, electric machines, power systems, and the Internet of Things.

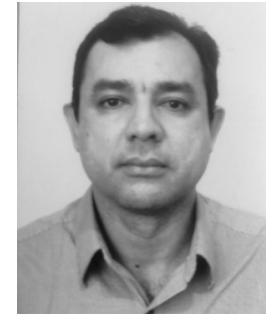

Jurandir de Oliveira Soares received the B.S. degree from the State and Pantanal Region Development University, Campo Grande, Brazil, and the M.S. and Ph.D. degrees from São Paulo State University, Ilha Solteira, Brazil, all in electrical engineering, in 2000, 2004, and 2008, respectively.

He is currently a Professor with the Faculty of Electrical Engineering, Federal University of Mato Grosso do Sul, Campo Grande, Brazil. His research interests include photovoltaic systems active powerfactor correction techniques, hybrid converters, digital control applied in ac-to-dc, dc-to-ac, and dc-to-dc converters.

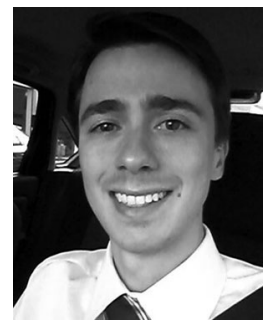

Pedro Eugênio Marcondes Justino Ribeiro received the B.E. and M.Sc. degrees in electrical engineering from the Federal University of Mato Grosso do Sul (UFMS), Campo Grande, Brazil, in 2009 and 2012 , respectively. He is currently working toward the Ph.D. degree in electrical engineering at the Federal University of Itajubá, Itajubá, Brazil.

$\mathrm{He}$ is currently also a Researcher in the BATLAB-Laboratory of Artificial Intelligence, Power Electronics and Digital Systems, UFMS, where he develops $R \& D$ projects in the areas of electrical engineering, power electronics and control systems, and artificial intelligence applications.

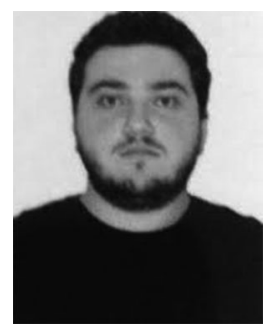

Leonardo A. Carniato received the B.S. and M.Sc. degrees in electrical engineering from the Federal University of Mato Grosso do Sul, Campo Grande, Brazil, in 2010 and 2013, respectively. He is currently working toward the Ph.D. degree in electrical engineering at São Paulo State University, Ilha Solteira, Brazil.

He is a currently a Professor in the São Paulo Federal Institute of Education, Science and Technology, Presidente Epitácio, Brazil. His research interests include distributed generation, microgrids, control theory and applications, switched systems, and robust control.

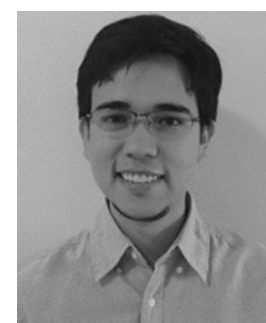

Marcio L. M. Kimpara was born in Jales, Brazil, in 1986. He received the B.S. and M.S. degrees from the Federal University of Mato Grosso do Sul (UFMS), Campo Grande, Brazil, in electrical engineering, in 2009 and 2012, respectively.

Since 2014, he has been an Assistant Professor at the UFMS.

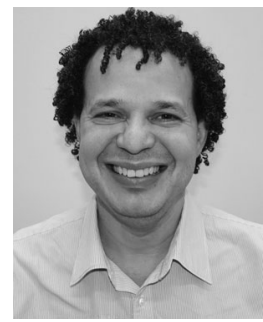

João O. P. Pinto (S'97-M'01-SM'12) was born in Valparaiso, Brazil. He received the B.S. degree in electrical engineering from São Paulo State University, Ilha Solteira, Brazil; the M.S. degree in electrical engineering from the Federal University of Uberlândia, Uberlândia, Brazil; and the Ph.D. degree in in electrical engineering from the University of Tennessee, Knoxville, TN, USA, in 1990, 1993 , and 2001, respectively.

He is currently a Faculty Member in the Federal University of Mato Grosso do Sul, Campo Grande, Brazil. His research interests include signal processing, neural networks, fuzzy logic, genetic algorithm, and wavelet applications to power electronics, pulsewidth modulation techniques, drives, and electric machine control. 


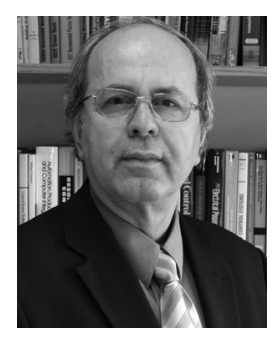

Kamal Al-Haddad (S'82-M'88-SM'92-F'07) received the B.Sc.A. and M.Sc.A. degrees in electrical engineering from the University of Québec à TroisRivières, Trois-Rivières, QC, Canada, and the Ph.D. degree in electrical engineering from the Institut $\mathrm{Na}-$ tional Polythechnique, Toulouse, France, in 1982, 1984 , and 1988, respectively.

Since June 1990, he has been a Professor with the Electrical Engineering Department, École de technologie supérieure, Montreal, QC, Canada, where, since 2002, he has been the holder of the Canada Research Chair in Electric Energy Conversion and Power Electronics. He is a Consultant and has established very solid link with many Canadian industries.

Dr. Al-Haddad is a Fellow Member of the Canadian Academy of Engineering. He is the IEEE IES President 2016-2017, the Associate Editor of the TRANSACTIONS ON INDUSTRIAL INFORMATICS, the IES Distinguished Lecturer, and the recipient of the Dr.-Ing. Eugene Mittelmann Achievement Award.

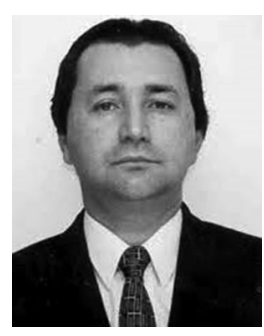

Carlos Alberto Canesin (S'87-M'97-SM'08) received the B.Sc. degree from the Faculdade de Engenharia de Ilha Solteira (FEIS), São Paulo State University (UNESP), Ilha Solteira, Brazil, and the M.Sc. and Ph.D. degrees from the Power Electronics Institute, Federal University of Santa Catarina, Florianópolis, Brazil, all in electrical engineering, in 1984, 1990, and 1996, respectively.

He started the Power Electronics Laboratory, FEIS, UNESP, where he is currently a Full Ph.D. Professor.

Dr. Canesin was the Editor-in-Chief of the Brazilian Journal of Power Electronics (in 2003-2004). From November 2004 to October 2006, he was the President of the Brazilian Power Electronics Society. Since 2003, he has been an Associate Editor of the IEEE TRANSACTIONS ON POWER ELECTRONICS and, since 2010, he has been a member of The State of São Paulo Council for Energy Policy. 